\title{
Interpersonal pragmatics: issues and debates
}

\author{
Michael Haugh (Griffith University) \\ Dániel Z. Kádár (University of Huddersfield) \\ Sara Mills (Sheffield Hallam University)
}

\section{A pragmatics perspective on interpersonal communication}

A pragmatics perspective on interpersonal aspects of communication and interaction has its roots largely in the work of Leech (1983) on "interpersonal rhetoric" and Brown and Levinson $(1978,1987)$ on "politeness" The former line of research is often couched nowadays as the broader subfield of "sociopragmatics" following Leech, while the latter constitutes the narrower subfield of "politeness research" following Brown and Levinson. Early work was dominated a focus on what might be broadly termed "identity-face" given politeness was generally conceptualised as attending to the "presentation and validation of the self" in some form or another following Goffman's ([1955]1967) highly influential account of face(work). However, in the past decade there has been a shift to reconceptualise politeness within a broader framework of relating or relationships, variously termed "relational work" (Locher and Watts, 2005, 2008), "rapport management" (Spencer-Oatey, [2000]2008, 2005, 2011), or "face constituting" (Arundale, 2006, 2010a, 2010b). This has, in turn, sparked the coalescing of various lines of research within pragmatics that focuses on such issues into a nascent grouping recently termed "interpersonal pragmatics" by Locher and Graham (2010). $\mathrm{Im} /$ politeness research nevertheless still plays a key role in grounding interpersonal pragmatics (cf. LPRG, 2011: 2). Indeed, we would argue that "(im)politeness" in a broader technical and scientific (cf. second-order) sense is largely synonymous with the analysis of many interpersonal aspects of communication. However, we would also argue that this move towards putting relationality or relationships to the forefront of interpersonal pragmatics research is nevertheless a very important one for pragmatics more broadly (Enfield, 2009). Thus, a post-Brown and Levinson discursive approach to the analysis of im/politeness is very much concerned with focusing on the way that status within relationships is signalled and marked by interactants, rather than assuming that politeness is simply a question, as Brown and Levinson approaches have posited, of indicating concern or respect for others (Kádár and Mills, 2011; Mills, forthcoming). Im/Politeness within this view is the means by which relationships are negotiated and contested/disrupted.

Interpersonal Communication, on the other hand, is part of the broader discipline of (North American) Communication that has flourished since the 1970s, although its roots go back to the work of Simmel, Mead, Heider, Goffman among others (Knapp, Miller and Fudge, 1994). Interpersonal Communication has traditionally been defined by its focus on "the process of creating social relationships between at least two people by acting in concert with one another" (Fisher and Adams 1994: 18). However, the field of Interpersonal Communication now has a multitude of theories (see, e.g., Baxter and Braithwaite, 2008 for a summary) and analytical foci (see Knapp and Daly, 2011 for a summary), which go beyond the traditional focus on personal relationships and mutual influenc" to encompass nonverbal behaviour, privacy, cognition, relational dialectics, and more recently, conflict and cooperation, social problems (e.g. social alienation, incivility), and the role of technologies in interpersonal communication (Knapp and Daly, 2011: 10). Yet with the exception of Brown and Levinson's politeness theory, the field of Interpersonal Communication on the whole has developed

\footnotetext{
${ }^{1}$ While Lakoff's $(1973,1975)$ early work on politeness is often cited as the beginnings of politeness research, the influence of her work has been primarily in research on gender and politeness (although see Mills, 2003), and thus has not been nearly as influential as the face-saving approach advanced by Brown and Levinson or the sociopragmatic approach advanced by Leech.
} 
largely independently of work in pragmatics on im/politeness, face(work) and relating - and indeed vice-versa - with surprising little in the way of cross-fertilisation to date.

Given the fact that the interests and analytical foci of researchers in Interpersonal Communication significantly overlap with those that have occupied researchers in pragmatics interested in $\mathrm{im} /$ politeness, face(work) and the like, we believe it is important that this nascent interest in interpersonal pragmatics does not develop into yet another sub-discipline in isolation of work in Interpersonal Communication. Instead, we propose that interpersonal pragmatics be conceptualised first and foremost as offering a pragmatics perspective on interpersonal aspects of communication and interaction. A pragmatics perspective naturally entails close and detailed examination of the ways in which "social actors use language to shape and form relationships in situ" (Locher and Graham 2010: 1), that is, careful analysis of both the role of "language in the creation of relationships" and on "how those relationships affect language use in turn" (p.3). On this view, interpersonal pragmatics is conceived of as inherently interdisciplinary or multidisciplinary in nature, and thus its aims are to build interfaces or bridges between the fields of Pragmatics and Communication and other related fields, not create yet further disciplinary boundaries. ${ }^{2}$

\section{On defining interpersonal pragmatics}

While Locher and Graham's (2010) definition of interpersonal pragmatics as the study of the ways in which "social actors use language to shape and form relationships in situ" (p.1) proves a useful starting point, careful examination of debates about what constitutes interpersonal communication in the neighbouring field of Communication also prove somewhat instructive. One such debate concerns the treatment of personal relationships in Interpersonal Communication as one context in which communication can be studied, versus the treatment of relationships as a process where interpersonal communication is seen as synonymous with the creation of interpersonal relationships (Knapp, Miller and Fudge 1994: 7). Antos, Ventola and Weber (2008), for instance, define interpersonal communication from a linguistic perspective as a focus on "how interactants manage to exchange facts, ideas, views, opinions, beliefs, etc. by using the linguistic system together with the resources it offers" (p.1). On this view, relating or relationships are implicitly conceptualised as a context in which communication arises and can be studied. Locher and Graham (2010), on the other hand, appear to align with a view of relationships as process given their explicit focus on the shaping and forming of relationships. This distinction arguably reflects, in turn, the two lay senses of interpersonal, namely, "relating to or involving relations between people" (cf. relationships as context), and "existing or happening between people" (cf. relationships as process) (Merriam-Webster Dictionary Online 2013). What appears at first glance to be a "technical" or "scientific" distinction thus evidently rests on appeals to "ordinary, everyday practices of talking about communication" (Craig 1999: 129). Elevating lay notions to the status of technical or scientific concepts without due caution creates various problems that have been the subject of much debate in politeness research over the past decade (e.g. Eelen 2001; Mills 2003; Watts 2003; cf. Haugh, 2012; Kádár and Haugh, 2013).

Given that such technical definitions in fact draw from lay understandings of interpersonal it is perhaps not surprising that one problem facing the definition of interpersonal relationships as a

\footnotetext{
${ }^{2}$ Interpersonal pragmatics, of course, goes beyond methods and research in Communication and pragmatics in intersecting with yet other disciplines as we shall see in this special issue. For instance, interpersonal pragmatics clearly intersects with other disciplines such as anthropology (e.g. Shults, 2003) and ethnography (e.g. Ellis, 2007), which have their own traditions in studying relationality. Widening the scope of our inquiry in this way is important because there are arguably some areas of interpersonal pragmatics, which can be more effectively approached by combining pragmatics with other areas, such as the analysis of ritual, which according to Kádár (2013), calls for an amalgamation of pragmatics and anthropological concepts.
} 
context for communication is that defining such contexts turns out to be a much more slippery affair than might first appear. Interpersonal communication is prototypically associated with (1) informal and unstructured interactions between (2) a minimum of two speakers in (3) close physical proximity exchanging (4) "idiosyncratic, personal and psychological information" (Knapp, Miller and Fudge 1994: 9). However, as Knapp, Miller and Fudge (1994) go on to point out, such a view is overly limiting given (1) interpersonal communication can also arise in institutional settings, such as between doctors and patients or in workplaces, (2) that "two-person interactions may be extensions of larger networks; the parties may have membership in a larger group and their conversation is subject to the structures and norms of that group" (p.8), (3) that it is now obvious that interpersonal communication can just as easily occur via various mediating technologies, and (4) "sociological and cultural information" can nevertheless play a key role in interpersonal communications (p.9). In other words, it often proves difficult in practice to distinguish between contexts in which interpersonal communication occurs and those in which it does not, thereby undermining the treatment of personal relationships as contexts in which communication occurs. Such observations also accord with previous claims by scholars such as Eelen (2001) who warn us to use labels such as 'interactants' and 'society' in a more critical way, and also with the increasing importance of alternative analytic categories such as communities of practice (Eckert and McConnell-Ginet, 1992; Mills, 2003), relational networks (Kádár and Haugh, 2013; Watts, 2003), and so on.

A problem facing the treatment of relationships as process, on the other hand, is that what counts as an interpersonal relationship is not as straightforward as it might seem either. Stewart (2009), for instance, argues that "the main characteristic of interpersonal communication is that the people involved are contacting each other as persons" (p.32, original emphasis), where to treat others as persons is to treat them as "a unique individual (not just role-filler or cultural representative)" (p.32). This is contrasted with "communication that is based on social roles and exchanges that minimize the presence of the communicators' personal identities...[to] connect in ways that emphasise their social roles - teller/customer, buyer/seller, server/diner and so on" (p.32), which he characterises as treating others impersonally as "role-fillers". In his view, then, persons are distinguished by their "uniqueness" as individuals, and interpersonal communication is a process by which interactants treat each as persons rather than impersonally vis-à-vis various social roles. However, while such a view might accord with North American understandings of personhood as an "independent, monadic self", it is less somewhat convincing in light of numerous other understandings of personhood or self in other cultures and societies where one's roles vis-à-vis others are seen as an integral part of an "interdependent" notion of self or personhood. Indeed, in much of the research about politeness to date, various social or interpersonal roles have proved to be integral to situated understandings of politeness, and so turn out to be a key interpersonal concern of participants in many instances. To understand how "social actors use language to shape and form relationships in situ" (Locher and Graham 2010: 1) or "the process of creating social relationships between at least two people" (Fisher and Adams 1994: 18) thus requires much more careful theorisation of what exactly we mean by persons and relationships.

This concern with roles and relationships chimes well with recent feminist debates about variables and identity. Rather than simply analysing a variable such as gender in the way that it determines certain language behaviours or styles, or the way that it impinges on judgments which are made about speakers, theorists have started to be more concerned with the way that gender is performed within interactions, the way that it is oriented to. Thus, the focus is less on the way that pre-determined elements such as gender impact on speakers and hearers, but rather the way that individuals draw on what they believe to be gender-appropriate behaviour or gender-contesting behaviour in order to construct a particular position for themselves, both as speakers and hearers. Thus, one's gender identity is not a fixed construction or interpretation but something which is negotiated with others and 
with one's conception of social norms. This is quite distinct from Stewart's individualistic view described above, as it is only through engagement with social and community of practice norms that individuals manage to negotiate positions for themselves within interaction. In this model, then, interactants are thoroughly social beings (Mills and Mullany, 2011).

This distinction between relationships as context versus process is also arguably critical because it directs or constrains, in turn, our conceptualisation of relationships as either exogenous or endogenous to communicative interaction. A view of relationships as exogenous to communication conceptualises them as something that drives interaction (as part of the "context" in which communication occurs), and so they can be studied by analysts from the perspectives (or subjectivities) of the individuals who are influenced by these relationships. A view of relationships as endogenous to communication conceptualises them as "emerg[ing] through and occur[ing] in the actions of both members of the relationship" (Fisher and Adams 1994: 18, original emphasis), from which it follows that the perspectives (or subjectivities) of individuals cannot be studied independently of the interactional context in which they arise.

It is worth noting that Brown and Levinson's theory of politeness is grounded in the former view of relationships as context, or at least it has been so utilised, given "power" and "distance" are generally treated as factors by which interactants figure out which politeness strategy is going to be most appropriate in a given context. On the discursive approach, however, im/politeness is conceptualised as one important means by which interactants establish, maintain as well as sometimes challenge or dispute their interpersonal relationships. What arguably lies at the core of such debates is whether our view of relationships primarily resides in the subjectivities of individual persons (a social psychological view) or in the intersubjectivities of two or more persons interlinked through ongoing interactions (a social constructivist view). While a pragmatist might be inclined to claim that the answer is simply that they reside in both, this evades the key question of where sociality ultimately resides.

If we accept Fisher and Adams's (1994) argument that "human relationships emerge through and occur in the actions of both members of the relationship, the interpersonal communication, or interactions" (p.18, original emphasis), and thus that "interpersonal communication does not consist solely of your actions, that is, of what you do to create relationship. Nor is it just what the other person does during the communication event...it is interaction created by both your actions and the other's action in concert with one another" (p.19), then, it appears the interpersonal nature of relating or relationships should direct us to focus on intersubjective understandings or interpretations of relationships first and foremost. The study of subjective understandings or interpretations on this view would thus be rooted in an examination of how they emerge in the process of forming such intersubjective interpretations or understandings. To date, the traditional social psychological view has arguably predominated in both Interpersonal Communication and in much work in Pragmatics. However, a "relational turn" in pragmatics (Enfield 2009) demands, we would suggest, much more careful examination of the intersubjective grounding of relating/relationships. This amounts, in turn, to a move towards treating subjective (i.e. individual or personalised) understandings of relationships as an outcome of the process of achieving intersubjectivity rather than something that drives communication or interaction, as is more often than not assumed. Such a focus on intersubjectivity also entails that we examine the way that the 'rules' for appropriate behaviour are forged in the negotiation of communicative of practice norms and those of the wider society, however difficult it might be to describe those wider ideologies of practice (Agha, 2007)

In sum, then, while we have largely problematized the definition of interpersonal communication and interpersonal pragmatics thus far, our aim has not been to needlessly deconstruct or critique, but rather to point out that a pragmatics perspective on interpersonal communication and interaction must inevitably wrestle with some key conceptual issues if it is to be truly productive. The first is that the 
conceptualisation of relationships and persons vis-à-vis those relationships needs more careful work, which examines how persons and relationships are realised in and through communication and interaction across relational and social networks, societies and cultures. The second is that we need to more carefully consider how we ground such understandings of persons and relationships vis-à-vis the intersubjective understandings achieved by two or more individuals through communication, and how we might treat subjective understandings as arising through the process of forming intersubjective understandings of relationships and persons-in-relationships. The lesson for at least some work in Interpersonal Communication from research in Pragmatics is that such theoretical or conceptual work is not as straightforward as might first appear when working within the bounds of a particular cultural setting and language (but cf. Carbaugh and van Over, this issue). The lesson for interpersonal pragmatics from research in Interpersonal Communication, as we shall see, is that restricting our conceptualisation of relationships to the positioning of self vis-à-vis others vastly underdetermines what relating/relationships involve (see also Spencer-Oatey, this issue, and the contributions to the "Forum on interpersonal relations", this issue), and also significantly downplays any examination of the role of the wider social group (or conceptions of appropriate behaviour) in determining language styles.

However, notwithstanding such theoretical debates, it is apparent that in interpersonal pragmatics, which encompasses a pragmatics perspective on interpersonal aspects of communication and interaction, there are three inter-penetrating areas that are of particular interest, namely, relational, attitudinal/emotive, and evaluative aspects of embodied language use. The primary area of concern in interpersonal pragmatics is naturally interpersonal relations, which encompasses "mutual social connections amongst people that are mediated by interaction, including power, intimacy, roles, rights and obligations" (Culpeper and Haugh, forthcoming). However, just as critical is the area of interpersonal attitudes, which encompasses "perspectives, usually value-laden and emotionally charged, on others that are mediated by interaction, including generosity, sympathy, like/dislike, disgust, fear and anger" (Culpeper and Haugh, forthcoming), and the very closely related, albeit emerging, area of interpersonal emotions, which encompasses embodied feelings or state-of-mind often characterised by participants as "irrational and subjective, unconscious rather than deliberate [and] genuine rather than artificial" (Edwards 1999: 273). ${ }^{3}$ Finally, there is a concern for interpersonal evaluations, which involve "appraisals or assessment of persons, or our relationships with those persons, which influence the way we think and feel about those persons and relationships, and consequently sometimes what we do" (Kádár and Haugh, 2013: 61) ${ }^{4}$. It is also worth noting that while while attitudinal, emotive/affective or evaluative aspects of interpersonal pragmatics can be understood as conceptually distinct from relational aspects (and vice-versa), they are nevertheless often intimately interlinked in situated interactions. This means that while face and im/politeness can be conceptually distinguished as being primarily instances of relational and evaluative work respectively (Haugh, 2013), for instance, in practice the analysis of face and im/politeness is often necessarily intertwined. Thus, while traditional areas of interest in pragmatics, such as im/politeness and face(work), do not straightforwardly map onto any one of these areas, we believe this to be an advantage as it reflects the complex, multi-faceted nature of both im/politeness and face(work).

\footnotetext{
${ }^{3}$ See also Kádár's (2013) work on the two-fold affective and emotive effect of relational practices such as rituals.

${ }^{4}$ More specifically, interpersonal evaluations involve "casting persons and relationships into certain valenced categories according to some kind of perceived normative scale or frame of reference" (Kádár and Haugh, 2013: $61)$.
} 


\section{Issues in interpersonal pragmatics}

In the previous section we have alluded to a number of issues that lie at the heart of a pragmatics perspective on interpersonal communication and interaction. In this section we consider four key issues, namely, the definition or conceptualisation of relationships, the role of meta-theory in interpersonal pragmatics, the treatment of interpersonal relationships vis-à-vis time, and finally the nature of the social or relational networks within which all such relational work arises, but through which such social or relational networks are themselves constituted.

The first issue is the question of how we conceptualise relating or relationships. As we have seen, relationships can be conceptualised, on the one hand, as the sum of two or more individuals interacting where the focus is on attending to each other's persons (i.e. socially constituted selves), following the social psychological tradition. On the other hand, they can be conceptualised as arising between two or more individuals, that is, as dialectically co-constituted and emergent phenomena distinct from persons-in-relationships following the social constructivist tradition (Arundale, 2010b).

On the former view, relating is primarily about performing or attending to social identities as they arise in interaction. Although there are important differences in their approaches to interpersonal aspects of communication, the notions of "relational work" (Locher and Watts, 2005, 2008), "relational practice" (Holmes and Marra, 2004), and "rapport management" (Spencer-Oatey [2000]2008) are united by their common focus on "ways in which people attend to the face needs of others" (Holmes, Marra and Vine, 2011: 83). ${ }^{5}$ A treatment of relating as performing or attending to social identities or "identity-face" (Spencer-Oatey, 2007; cf. Garcés-Conejos Blitvich, 2013), generally leads to a focus on the way interpersonal communication systems "regulate consensus with respect to individual's self-conception", thereby directing most analytical attention to the "development, presentation, and validation of self-conceptions" (Cushman and Craig 1976: 44). This grounds, in turn, a natural tendency towards examining the "the cognitive antecedents and consequences of individuals' communicative attempts to exert influence within their close relationships" (Roloff and Anatasiou, 2001: 53). It is important to note, however, that a focus on performing/attending to social identities is not necessarily inconsistent with a discursive approach, but simply that conceptualising relationships as achieved through mutual positioning of self and other visà-vis self and other grounds the primary locus of analysis in the understandings of individuals. This naturally leads to the common, but what Knapp, Miller and Fudge (1994) consider "questionable" practice of "gathering data about a particular two-person interaction or two-person interactions in general by asking individuals to provide the data" (p.8, original emphasis; see also Arundale, 2010b). The question that arises here is whether we can really get a complete picture of interpersonal relations through methods that generate data from the (self-reporting) of individuals.

On the latter view, relating is conceptualised as "a social system of interrelated behaviours connecting individuals", which given it is a social system "cannot be reduced to its component parts and has an identity separate from the sum of those parts" (Fisher and Adams, 1994: 20). Although there are substantial differences in their approaches to interpersonal aspects of communication, the notions of "relational connection-separation" (Arundale 2006, 2010a, 2010b) and "relational dialectics" (Spencer Oatey, 2011, this issue) are united in their assumption that relating and relationships should be treated as concerns distinct and separate from social identities, identity-face

\footnotetext{
${ }^{5}$ What differentiates these approaches, as Spencer-Oatey (2011: 3576) argues, is their respective focus on "strategic relations", that is, "the power relations and distance/closeness relations of the participants of participants, and on the ways in which these elements are negotiated, challenged, upheld and so on", "sociality relations", that is, "pro-social behaviour...that promotes helping, benefiting and co-operation with others", or "rapport relations", that is, "the affective quality of people's relations, such as positive/negative, smooth/turbulent, warm/antagonistic" (Spencer-Oatey, 2011: 3576).
} 
and other person-centred notions. A treatment of relating as a "social system" generally leads to a focus on relationships as "dynamic, on-going, ever-changing, continuous" that can be likened to "the fluid ebb and flow of a dance" (Fisher and Adams, 1994: 20), and thus the ways in which messages are sequenced into conversations and the "sequencing of conversations into relationships" (Pearce, 1976: 17). This grounds, in turn, a natural tendency towards examining the interactional antecedents (and consequences) of this fluid ebb and flow of relational work. It is important to note, however, that a focus on relating vis-à-vis relational dialectics is not necessarily consistent with a discursive approach, as this depends on how such a conceptualisation is instantiated in analysis, but simply that conceptualising relationships as emerging through the actions of two or persons in concert grounds the primary locus of analysis of relating in the interactionally achieved understandings of two or more individuals. What it does certainly lead to, however, is the treatment of a two-person social system (i.e. relational dyad) as the minimum unit of analysis (Arundale, 2010a, 2010b). ${ }^{6}$ What this means in practice is that understandings of relationships achieved through interaction by two or more individuals are treated as the primary site for analysis of relationships, while self-reports of individuals are considered a secondary, albeit sometimes quite useful, site for analysis. As Enfield (2009) has recently argued in his call for a greater focus on "relationship thinking" in pragmatics, "every interaction increments an interpersonal relationship by means of building common experience, and displays the nature of that relationship such that it may be evaluated by participants and onlookers" (p.72). ${ }^{7}$ On this view, "relationships are a primary locus of social organisation" and thus should be "a key focus for pragmatics" (p.60), alongside the traditional focus on the social constitution of self or identity-face. A number of the contributions to this special issue advance our understanding of relating in differents ways, or in some cases raise important questions we need to consider further.

A second key issue is the role of meta-theory. Fitzpatrick (1993) has argued in relation to the field of Interpersonal Communication that it needs to maintain both a "social dimension" as well as a "scientific foundation" (p.18). She suggests that without a "scientific foundation", analysts "will be unable to specify how to judge among competing claims" (p.19). On the other hand, without a wellgrounded "interpretive approach", analysts "may miss the broader social issues of theory and thus perpetuate social structures" (p.19). Such arguments have been advanced already in relation to $\mathrm{im} /$ politeness (see, for example, Mills, 2003, 2009). However, the need for some kind of theoretical or analytical framework is not without its problems. The wide range of theories, models, frameworks, approaches in im/politeness research, for instance, could be interpreted as a sign of a flourishing field. However, without a meta-theoretical framework in which to couch debates, such diversity can lead (on a less charitable interpretation) to "sterile eclecticism" (Craig 1999) where various strands of research in im/politeness end up being "incommensurable" in the sense that "they neither agree nor disagree about anything, but effectively bypass each other because they conceive of their nominally shared topic...in such fundamentally different ways" (Craig, 1999: 121; see also Mills, 2011a: 20, fn.3). Even if we take a more charitable stance on the current state-of-play in im/politeness research, and treat this diversity as a form of "productive fragmentation" where various approaches are seemingly productive in their own domain (i.e. on their own terms), this nevertheless leaves the problem that "the fragments $\mathrm{d}[\mathrm{o}]$ not and could never, in the ways they [are] used, cohere as a selfsustaining whole that [is] something more than the sum of its parts" (Craig, 1999: 123). It is worth

\footnotetext{
${ }^{6}$ This does not mean that we should only be studying relationships in two-person interactions as has sometimes been mistakenly assumed (cf. Hahn and Hatfield, 2011: 26, 58), but rather that no matter how many people might be involved in the interaction in question, the minimum loci for analysis must be the interleaving interactional contributions of at least two of those people, not simply the self-reports of just one of them. ${ }^{7}$ This fits neatly within a discursive approach to im/politeness which, as mentioned above, concerns itself with the analysis of the display in interaction of an awareness of status and relationship.
} 
noting that a meta-theory of interpersonal pragmatics is not of the same order as a theory of politeness, face, relating or the like. The aim of a meta-theory is not "integrate" various theories, but rather "opens up a conceptual space in which diverse first-order models can interact, and a conception of [interpersonal] communication theory as theoretical metadiscourse [is] productively engaged with the practical metadiscourse of everyday life" (Craig, 1999: 121; see also Kádár and Haugh, 2013: 102-103). A meta-theory of interpersonal pragmatics is arguably necessary, although we do not have the space here to develop such a framework. However, the fragmented beginnings of such a metatheory can be gleaned, we believe, from the many and varied contributions to this special issue.

A third issue is the question of how the analysis of interpersonal relations should be situated vis-àvis time (Arundale, 2010a, 2010b; Mills, 2003; Sifianou, 2012; Werner and Baxter, 1994). A common perspective to date has been an understanding of time as punctuated. Relationships on this view are treated as a discrete, independent summative product of interpretations by the speaker or the hearer. However, time can also be understood in the sense of what Garfinkel (1967: 41) termed "the retrospective-prospective sense of a present occurrence." This is an understanding of time as emergent. Relationships on this view of time are understood as an interleaving, interdependent nonsummative product of the participants reciprocally affording and constraining the interpretations or understandings of the other (Arundale and Good, 2002). Moreover, there is a third sense of time that is important for understanding relationships situated in the here-and-now, namely, the ongoing linking of moments of here-and-now over time. This is an understanding of time as infused with historicity (Blommaert, 2005, Kádár, in press). Relationships on this view of time are understood as inter-related with relationships in the there-and-then vis-à-vis the relational history of those participants, as well as through the broader relational network of which they are a part (Kádár and Haugh, 2013: 74-77). Notably, approaching relationships through the concept of historicity provides an important bridge between interpersonal pragmatics and social philosophy, in particular Martin Heidegger's existential philosophy (1927 [1962]).

Issues of time also have important implications for the units of analysis considered appropriate in interpersonal pragmatics. While such choices are naturally driven by the nature of the research question in hand, the importance of relational histories (and the impact of relational histories on perceived interactional or communicative norms) across both prior interactions and relational networks for analysing interpersonal phenomenabecomes evident from a number of papers in this special issue, thereby underscoring the need for more studies of interpersonal relations across interlinked interactions (e.g. Clark, 2011) in interpersonal pragmatics. And although the analysis of this issue is beyond the scope of the present special issue, conceptualising relationships through the lens of historicity also raises the importance of looking into the roots of certain interactional behaviours beyond the confines of interpersonal relationships as instantiated in local interactions, to those situated within the habitus (Bourdieu 1977) of the broader relational network or societal milieu of those interactants.

A final key issue in interpersonal pragmatics is the loci of analysis. As we have already noted, interpersonal communication necessarily presupposes the involvement of a minimum of two individuals, although it can, of course, involve (many) more than two individuals. This naturally moves the loci of analysis to, at a minimum, a dyadic relational system, but also more often than not relative to broader Communities of Practice (Mills, 2003, 2011b) or relational networks (Locher, 2004; Kádár and Haugh, 2013; Watts, 2003), alongside the more traditional focus in politeness research on cultures and societies (Bargiela-Chiappini and Kádár, 2011; Kádár and Mills, 2011). As Haugh, Davies and Merrison (2011: 1) argue, politeness, and thus relational concerns more broadly, can be situated relative to various kinds of contrasts (e.g. across cultural groups, languages, dialects or genres), within particular settings (e.g. educational, medical, or legal contexts), and vis-à-vis different text types (e.g. computer-mediated discourse, media discourse, advertising texts). Levinson's (2006) 
proposal that there are three interdependent ontological levels that need to be considered in analysing complex sociocultural phenomena, namely, the individual level, the interactional level and the sociocultural level, arguably offers a useful heuristic in that respect. Yet whilst it is useful to focus on these three levels and to ensure that our analysis equally addresses them, it is important also to be aware that it is not possible to always - or even ever - distinguish between the impact of these levels. The socio-cultural level is manifest at the individual and interactional level and cannot be disentangled from them. Individuals negotiate and try out with others their conception of what the sociocultural norms are, and those sociocultural norms are themselves affirmed or tested/challenged and changed by the linguistic behaviour at the level of the interaction and the individual. We would caution, then, that the primary locus for analysis in interpersonal pragmatics should be grounded with respect to the interactional level, even in studies that primarily focus on either the individual or sociocultural levels, as a number of contributions to this special issue suggest. Numerous questions remain, however, as to how we might situate the analysis interpersonal relations, attitudes, emotions/affection and evaluations vis-à-vis different kinds of social or relational systems, questions which a pragmatic perspective can arguably productively contribute towards through close analyses of how such social or relational systems are constituted in and through the use of language.

\section{Interpersonal pragmatics: overview of the issue}

This issue begins with three contributions that all focus on issues of data and how such data is analysed and theorised. We thus begin this special issue by raising questions about what constitutes data for research in interpersonal communication, a point that is also returned to the final reflective paper on the role of language in interpersonal pragmatics by O'Driscoll.

The first paper in this section by Arundale, "Conceptualising interaction in interpersonal pragmatics: consequences for understanding and research", considers the critical implications that the particular metaphor or model utilised in conceptualising "interaction" has for the ways in which for both theorisation and analysis in interpersonal pragmatics proceeds. In particular, it is argued that research in interpersonal pragmatics needs to account for, but also go beyond treatments of interaction as aggregations of utterances by individual participants.

The second paper, "Of babies and bath water: is there any place for Austin and Grice in interpersonal pragmatics?" by Grainger engages with the question of whether approaches to analysis in first-wave approaches, such as those of Austin and Grice, might more productively inform subsequent discursive approaches to the analysis of interpersonal aspects of interaction. Grainger argues that while many of the assumption of such first-wave approaches to politeness, for instance, have been rightly challenged by discursive theorists, close examination of analyses undertaken under a discursive or post-modern umbrella reveals that such analyses are not always adequately evidenced, and then suggests that first-wave approaches offer analytical tools which prove useful in teasing out such analytical evidence.

The final contribution in this first section on the role of data and theory in interpersonal pragmatics is the discussion forum on "Sensory pragmatics" led by Bargiela-Chiappini, and which features responses from Cooren ("Incarnation, sensation and ventriloquilism: for a sensitive and constitutive view of pragmatics"), Crossley ("Mead, Merleau-Ponty and embodied communication") and Majid ("Making semantics and pragmatics "sensory"). A common theme across these contributions is that an understanding of interpersonal communication must go beyond the confines of language and the analysis of intersubjective understandings to a consideration of the ways in which participants themselves perceive and experience communication as embodied social beings. Yet the arguments advanced in this discussion forum go beyond advocating a move to the analysis of the organisation of social bodies and corporeal language alongside the traditional focus in pragmatics on language-in-use 
(albeit in context). Indeed, what is illustrated here is that the realm of embodied subjectivity enters into the realm of embodied intersubjectivity in a multitude of ways. In other words, we cannot ignore how participants themselves perceive and experience interaction even if such perceptions and experiences do not necessarily straightforwardly surface in the intersubjective record of interaction.

The second part of the special issue moves into a consideration of the various analytical foci of research in interpersonal pragmatics. As the contributions here illustrate, while these include a focus on the now oft-traversed paths of research on im/politeness and face, interpersonal pragmatics encompasses an expanded focus on emotions, relationships, rituals and social indexicality vis-à-vis stance and identities.

This expanded focus is reflected in the first paper in this section by Haugh, "Im/politeness, social practice and the participation order", where it is argued that the notion of evaluation, which is often referred to in discursive accounts of im/politeness, has remained somewhat under-theorised to date, and thus more careful analysis of how evaluations can themselves become the object of evaluation, and how social actions and meanings are themselves very often implicitly evaluative requires further attention. He also suggests that a move towards an account of im/politeness within a broader interpersonal pragmatics framework requires more careful analysis of the participation order within which such evaluations arise, as it is only in this way that we can account for their distributed, variable and cumulative nature.

In the next paper by Kádár and Bax, "In-group ritual and relational work", the scope of interpersonal pragmatics is broadened to include ritual practices that arise within relational networks. It is illustrated that a focus on rituals necessitates a different approach to analysis that takes into account the ways in which interactions in particular moments in time are nevertheless imbued with historicity, that is, with a relational history, which in the case of in-group rituals, is distributed across a relational network. Kádár and Bax thus offer a considerably expanded notion of ritual that goes beyond the traditional folk conceptualisation of it as a kind of formalised social routine, thereby demonstrating the importance of analysing rituals in the context of interpersonal relationships.

While alluded to in the discussion of in-group rituals, the move to focus on analysing emotions in interpersonal communication is explicitly addressed in the following paper by Langlotz and Locher, "The role of emotions in relational work". In their paper they first overview work on emotions to date that usefully informs a pragmatics perspective on emotive aspects of relational work, and then proceed to propose a multimodal framework by which analysts committed to the tenets of a discursive approach might develop an analysis of the display of emotions by participants. One of their key arguments is that emotions are signalled through composite signals that do not privilege verbal talk. A second key claim is that our understanding of interpersonal relationships necessarily draws upon an analysis of the display of emotions in interaction, and thus the analysis of displays of emotions should play a central role in interpersonal pragmatics.

The argument that face constitutes an important focus of study in its own right, independent of the ways in which it has been invoked in im/politeness research to date (Haugh and Bargiela-Chiappini, 2010; Haugh, 2013; O'Driscoll, 2011), is furthered in a second contribution by Arundale, "Face as a research focus in interpersonal pragmatics: relational and emic perspectives". Arundale addresses the issue of how emic conceptualisations of face might be accommodated within a culture-general, theoretical account of face, namely, that developed in Face Constituting Theory (FCT) (Arundale, 1999, 2010a). He grounds this discussion in an analysis of how the Japanese emic conceptualisation of face can be articulated vis-à-vis FCT, suggesting that while these folk and theoretical accounts are not synonymous given the latter couches face in relational rather than individual terms, they are nevertheless compatible with each other. On Arundale's account, then, it is to reconcile culturegeneral and culture-specific accounts of face, a resolution which has proved elusive in the history of pragmatics thus far. 
The centrality of relationships for interpersonal pragmatics is then further addressed in the paper by Spencer-Oatey, "Relating at work: facets, dialectics and face". Drawing from an empirical study of participants reports about relationships in the workplace, Spencer-Oatey argues that the study of relationships or relating in interpersonal pragmatics needs to go beyond an account of relationships vis-à-vis face. She suggests that the relational dialectics approach of Baxter and Montgomery (1996) has much to offer in that respect in untangling the current conflation of "facework" with "relational work".

Spencer-Oatey's paper then seeds a second discussion forum on "Interpersonal relations", which features a response by Arundale to Spencer-Oatey's claim that face has been conflated with relating ("Face, relating and dialectics: a response to Spencer-Oatey"), followed by a discussion note from Carbaugh and van Over ("Interpersonal pragmatics and cultural discourse") that raises the issue of culturally-nuanced understandings play in relating, and an overview by Locher ("Relational work and interpersonal pragmatics") of how relationships are approached in a discursive approach. SpencerOatey then briefly addresses some of the issues raised in this discussion forum in a piece, "Further reflections on 'relating' and 'face'. A response to Arundale, Carbaugh and Locher', that considers how different conceptualisations of face and relating underpin these different responses, and how we are currently constrained by the "paucity of terminology in English" to tease out different facets of relating and face.

This section on analytical foci in interpersonal pragmatics then concludes with a paper by Christie, "The relevance of taboo language: an analysis of the indexical values of swearwords", which considers how particular linguistic expressions, namely, swearwords, produce im/politeness effects through a complex array of socially-mediated meanings. She illustrates how the interpretation of the use of swearwords in particular situated contexts necessarily draws on a much broader indexical field that is informed by ideologies vis-à-vis swearing. Importantly, these ideologies arise through "regularities of evaluative behaviour" (Agha, 2003: 242), and thus in this way we can chart how particular linguistic expressions are imbued with socially recognisable interpersonal force(s).

The special issue is then rounded out with a contribution by O'Driscoll, "The role of language in interpersonal pragmatics". While it is not a traditional epilogue as such, it nevertheless draws together a highly perceptive account of what traditions have informed interpersonal pragmatics to date, namely, linguistic pragmatics, and how those working within an interpersonal pragmatics paradigm have moved beyond a singular focus on language-in-use. O'Driscoll takes this observation further, however, in suggesting that researchers in interpersonal pragmatics would be well advised to eschew the traditional bias towards examining language use in context, which many assume to be the central focus of pragmatics, towards an account of situated contexts from which we proceed to burrow down into an analysis of the details of interaction. In this way, we start to see that an account of "human social life and interaction" (Brown and Levinson, 1987: 1), towards which research in interpersonal pragmatics can arguably make an important contribution, must take social relations rather than units of language-use as the most appropriate starting point for framing our analyses of interpersonal aspects of interaction.

\section{Concluding remarks}

From the many and varied interfaces between pragmatics and other disciplines drawn upon by papers in this special issue, it is clear that interpersonal pragmatics is by definition an interdisciplinary enterprise, and thus at its heart involves working at disciplinary interfaces. These interface include between Pragmatics and (North American) Communication (Arundale; Carbaugh and van Over; Spencer-Oatey; Cooren), including cultural discourse analysis and organisational communication as subfields within Communication; Interactional sociolinguistics (Grainger; Locher); Phenomenology 
and embodied cognition (Bargiela-Chiappini; Cooren; Crossley; Majid); Ethnomethodological Conversation Analysis and Discursive Psychology (Haugh; Bargiela-Chiappini); Social cognition (Langlotz and Locher); Anthropology (Kádár and Bax); and Sociolinguistics (Christie). Given the wide range of disciplines from which these papers draw it becomes evident that interpersonal pragmatics should be understood as a perspective that is inevitably multidisciplinary or interdisciplinary in nature. However, we argue that it nevertheless has much to offer that complements, as well as sometimes challenges, existing approaches to interpersonal communication.

In conclusion, we suggest that treating interpersonal pragmatics as a perspective has two key advantages. First, it helps us to avoid the ever-increasing problem in scholarly work of "putting old wine into new bottles", that is, simply re-lexicalising old concepts or re-situating extant understandings in new ways without contributing to more developed or nuanced understandings of those old concepts and extant understandings. In this way, we can avoid falling into the trap of simply recycling old ideas in new guises, and thereby avoid perpetuating potential confusion and increasing fragmentation of academic disciplines into isolated subdisciplines. Second, it arguably allows to also better mine the rich and nuanced accounts of original thinkers like Bourdieu, Foucault, Grice, Goffman, Garfinkel, Gumperz and Merleu-Ponty to name a few, as well as to draw, where appropriate, from the work undertaken in Interpersonal Communication more broadly. In this way, we can develop this rich intellectual inheritance in ways that advance our understanding of the ways in which interpersonal aspects of communication and interaction are realised through language-in-use.

\section{Acknowledgements}

We would like to express our thanks to Sheffield Hallam University for sponsoring the one-day symposium held on $29^{\text {th }}$ June 2011 from which this special issue developed, and Sara Mills, in particular, for her generous support of this event.

\section{References}

Agha, Asif, 2003. The social life of cultural value. Language and Communication 23 (3/4), 231-273.

Agha, Asif, 2007. Language and Social Relations. Cambridge University Press, Cambridge.

Antos, Gerd, Ventola, Eija, Weber, Tilo, 2008. Introduction: Interpersonal communication - linguistic points of view. In: Antos, G. Ventola, E. Weber, T. (Eds.), Handbook of Interpersonal Communication. Mouton de Gruyter, Berlin, pp.1-11.

Arundale, Robert, 1999. An alternative model and ideology of communication for an alternative to politeness theory. Pragmatics 9 (1), 119-154.

Arundale, Robert, 2006. Face as relational and interactional: a communication framework for research on face, facework, and politeness Journal of Politeness Research 2 (2) 193-216.

Arundale, Robert, 2010a. Constituting face in conversation: face, facework and interactional achievement Journal of Pragmatics 42 (8), 2078-2105.

Arundale, Robert, 2010b. Relating. In: Locher, M. A., Graham, S. L. (Eds.), Interpersonal Pragmatics. Mouton de Gruyter, Berlin, pp. 137-165.

Arundale, Robert, Good, David, 2002. Boundaries and sequences in studying conversation. In: Fetzer, A., Meierkord, C. (Eds.), Rethinking Sequentiality. Linguistics Meets Conversational Interaction. John Benjamins, Amsterdam, pp. 121-150.

Bargiela-Chiappini, Francesca, Kádár, Dániel Z., eds, 2011. Politeness across cultures. Palgrave 
Macmillan, Houndmills, Basingstoke.

Baxter, Leslie A., Braithwaite, Dawn O., 2008. Engaging Theories in Interpersonal Communication. Sage, Thousand Oaks, CA.

Baxter, Leslie, Montgomery, Barbara, 1996. Relating: Dialogues and Dialectics. Guilford Press, New York.

Blommaert, Jan, 2005. Discourse: A critical introduction. Cambridge University Press, Cambridge.

Bourdieu, Pierre. 1977. Outline of a Theory of Practice. Cambridge University Press, Cambridge.

Brown, Penelope, Levinson, Stephen, 1978. Universals in language usage: politeness phenomena. In: Goody, E. (Ed.), Questions and Politeness. Cambridge University Press, Cambridge, pp. 56-311.

Brown, Penelope, Levinson, Stephen, 1987. Politeness. Some Universals in Language Usage.

Cambridge University Press, Cambridge.

Carbaugh, Donal, van Over, Brion, this issue. Interpersonal pragmatics and cultural discourse.

Clark, Jody, 2011. Relational work in a sporting community of practice. In: Davies, Bethan, Haugh, Michael, Merrison, Andrew J. (eds.), Situated Politeness. Continuum, London, pp. 88-109.

Craig, Robert T., 1999. Communication theory as a field. Communication Theory 9 (2), 119-161.

Culpeper, Jonathan, Haugh, Michael, forthcoming. Pragmatics and the English Language. Palgrave Macmillan, Houndmills, Basingstoke.

Cushman, Donald P., Craig, Robert, T., 1976. Communication systems: interpersonal implications. In: Miller, Gerald R. (ed.), Explorations in Interpersonal Communication. Sage, Beverley Hills, CA, pp. $37-58$.

Eckert, Penelope, McConnell-Ginet, Sally, 1992. Think Practically and Look Locally: Language and Gender as Community- Based Practice. Annual Review of Anthropology 21, 461-490.

Edwards, Derek, 1999. Emotion discourse. Culture \& Psychology 5(3), 271-291.

Eelen, Gino, 2001. A Critique of Politeness Theories. St Jerome, Manchester.

Ellis, Carolyn, 2007. Telling Secrets, Revealing Lives: Relational Ethics in Research With Intimate Others. Qualitative Inquiry 13(1), 3-29.

Enfield, N. J., 2009. Relationship thinking and human pragmatics. Journal of Pragmatics 41 (1), 6078.

Fisher, Aubrey B., Adams, Katherine L., 1994. Interpersonal Communication. Pragmatics of Human Relationships. McGraw-Hill, New York.

Fitzpatrick, Mary Anne, 1993. Communication and the New World of Relationships. Journal of Communication 43 (3), 119-126.

Garcés-Conejos Blitvich, Pilar, 2013. Introduction: Face, identity and politeness. Looking backward, moving forward: from Goffman to practice theory. Journal of Politeness Research 9(1), 1-33. 
Garfinkel, Harold, 1967. Studies in Ethnomethodology. Prentice-Hall, Englewood Cliffs, NJ.

Goffman, Erving, [1955]1967. On face-work: an analysis of ritual elements in social interaction. In: Goffman, E (Ed.), Interaction Ritual. Pantheon, New York, pp. 5-45.

Hahn, Jee-Won, Hatfield, Hunter, 2011. Group face in Korea and the United States: taking responsibility for the individual and the group. Multilingua 30 (1), 25-70.

Haugh, Michael, 2012. Epilogue: The first-second order distinction in face and politeness research. Journal of Politeness Research 8 (1), 111-134.

Haugh, Michael, 2013. Disentangling face, facework and im/politeness. Sociocultural Pragmatics $1(1), 46-73$.

Haugh, Michael, Bargiela-Chiappini, Francesca, 2010. Face in interaction. Journal of Pragmatics 42(8), 2073-2077.

Haugh, Michael, Davies, Bethan, Merrison, Andrew John, 2011. Situated Politeness. In: Davies, B., Haugh, M., Merrison, A. J. (Eds.) Situated Politeness. Continuum, London, pp. 1-23.

Heidegger, Martin 1927 [1962] . Sein und Zeit (Being and Time). Trans. John Macquarrie. State University of New York Press, New York.

Holmes, Janet, Marra, Meredith, 2004. Relational practice in the workplace: women's talk or gendered discourse? Language in Society 33(3), 377-398.

Holmes, Janet, Marra, Meredith, Vine, Bernadette, 2011. Leadership, Discourse and Ethnicity. Oxford University Press, Oxford.

Kádár, Dániel Z. 2013. Relational Rituals and Communication: Ritual Interaction in Groups. Basingstoke: Palgrave Macmillan.

Kádár, Dániel Z. in press. Historical Politeness. In: Jef Verschueren, J, Östman, J. O. (Eds.) Handbook of Pragmatics. John Benjamins, Amsterdam.

Kádár, Dániel Z., Haugh, Michael, 2013. Understanding Politeness. Cambridge University Press, Cambridge.

Kádár, Dániel Z., Mills, Sara, 2011. Introduction. In: Kádár, D. Z., Mills, S. (Eds.), Politeness in East Asia. Cambridge University Press, Cambridge, pp. 1-17.

Knapp, Mark, Daly, John, 2011. Background and current trends in the study of interpersonal communication. In: Knapp, Mark, Daly, John A., (Eds.) Handbook of Interpersonal Communication (4th edn). Sage, Thousand Oaks, CA, pp.3-22.

Knapp, Mark, Miller, Gerald, Fudge, Kelly, 1994. Background and current trends in the study of interpersonal communication. In: Knapp, Mark, Miller, Gerald, R. (Eds.), Handbook of Interpersonal Communication ( $2^{\text {nd }}$ edn). Sage, Thousand Oaks, CA, pp.3-24.

Lakoff, Robin, 1973. The logic of politeness; or minding your p's and q's. Chicago Linguistics Society 9, 292-305. 
Lakoff, Robin, 1975. Language and Women's Place. Harper \& Row, New York.

Leech, Geoffrey, 1983. Principles of Pragmatics. Longman, London.

Levinson, Stephen, 2006. Cognition at the heart of human interaction. Discourse Studies 8(1), 85-93.

Linguistic Politeness Research Group (Eds.), 2011. Introduction: the Linguistic Politeness Research Group. In: Linguistic Politeness Research Group (Eds.) Discursive Approaches to Politeness. Mouton DeGruyter, Berlin, pp. 1-17.

Locher, Miriam A., 2004. Power and Politeness in Action: Disagreements in Oral Communication. Mouton de Gruyter, Berlin.

Locher, Miriam A., Graham, Sage L., 2010. Introduction to Interpersonal Pragmatics. In Locher, M., Graham, S. (Eds.), Interpersonal Pragmatics. Mouton de Gruyter, Berlin, pp. 1-13.

Locher, Miriam, Watts, Richard, 2005. Politeness theory and relational work. Journal of Politeness Research 1 (1), 9-34.

Locher, Miriam, Watts, Richard, 2008. Relational work and impoliteness: negotiating norms of linguistic behaviour. In: Bousfield, D., Locher, M. (Eds.), Impoliteness in Language. Mouton de Gruyter, Berlin, pp. 77-99.

Mills, Sara, 2003. Gender and Politeness. Studies in Interactional Sociolinguistics. Cambridge University Press, Cambridge.

Mills, Sara, 2009. Impoliteness in a cultural context. Journal of Pragmatics 41 (5), 1047-1060.

Mills, Sara, 2011a. Discursive approaches to politeness and impoliteness. In: LPRG (ed.), Discursive Approaches to Politeness. Mouton de Gruyter, Berlin, pp. 19-56.

Mills, Sara, 2011b. Communities of practice and politeness. In: Davies, Bethan, Haugh, Michael, Merrison, Andrew J. (eds.), Situated Politeness. Continuum, London, pp. 73-87.

Mills, Sara, forthcoming. Beyond English Politeness.

Mills, Sara, Mullany, Louise, 2011. Language Gender and Feminism. Routledge, London.

O'Driscoll, Jim, 2011. Some issues with the concept of face: when, what, how and how much? In: Bargiela-Chiappini, Francesca, Kádár, Dániel Z. (Eds.), Politeness across Cultures. Palgrave Macmillan, Basingstoke, pp. 17-41.

Pearce, W. Barnett, 1976. The coordinated management of meaning. In: Miller, Gerald R. (ed.), Explorations in Interpersonal Communication. Sage, Beverley Hills, CA, pp. 17-36.

Roloff, Michael E., Anatasiou, Lefki, 2001. Interpersonal communication research: an overview. In: Gudykunst, W. B. (Ed.), Communication Yearbook 24, Sage, Thousand Oaks, pp. 51-71.

Shults, F. Leron, 2003. Reforming Theological Anthropology: After the Philosophical Turn to Relationality.Wm. B. Eerdmans Publishing, Michigan.

Sifianou, Maria, 2012. Disagreements, face and politeness. Journal of Pragmatics 44 (12), 1554-1564. 
Spencer-Oatey [2000]2008. Face, (im)politeness and rapport. In: Spencer-Oatey, H. (ed.), Culturally Speaking. Culture, Communication and Politeness Theory ( $2^{\text {nd }}$ edn). Continuum, London, pp. 11-47.

Spencer-Oatey, Helen, 2005. (Im)Politeness, face and perceptions of rapport: unpackaging their bases and interrelationships. Journal of Politeness Research 1 (1), 95-120.

Spencer-Oatey, Helen, 2007. Theories of identity and the analysis of face. Journal of Pragmatics 39 (4), 639-656.

Spencer-Oatey, Helen, 2011. Conceptualising 'the relational' in pragmatics: Insights from metapragmatic emotion and (im)politeness comments. Journal of Pragmatics 43 (14), 3565-3578.

Spencer-Oatey, Helen, this issue. Relating at work: facets, dialectics and face.

Stewart, John, 2009. Communication and interpersonal communication. In: Stewart, J. (ed.), Build Bridges, Not Walls. A Book about Interpersonal Communication (10th edn). McGraw-Hill, Boston, MA, pp. 15-38.

Watts, Richard, 2003. Politeness. Cambridge University Press, Cambridge.

Werner, Carol, M., Baxter, Leslie A., 1994. Temporal qualities of relationships: organismic, transactional, and dialectical views. In: Knapp, Mark, Miller, Gerald, R. (Eds.), Handbook of Interpersonal Communication ( $2^{\text {nd }}$ edn). Sage, Thousand Oaks, CA, pp. 323-379.

\section{Editor bionotes}

Michael Haugh is an Associate Professor in Linguistics and International English in the School of Languages and Linguistics at Griffith University, Brisbane, Australia. His areas of research interest include face, im/politeness, humour, intention and implicature, drawing from both interactional and discursive perspectives. He has edited a number of journal special issues, including "Intention in pragmatics" for Intercultural Pragmatics (2008), "Conceptualisations of communication" for Australian Journal of Linguistics (2009), "Face in interaction" (2010) and "Im/politeness across Englishes" (2012) for Journal of Pragmatics, as well as co-editing Face, Communication and Social Interaction (2009, Equinox) and Situated Politeness (2011, Continuum).

Dániel Z. Kádár is Professor of English Language and Linguistics and Director of Centre for Intercultural Politeness Research at the University of Huddersfield, U.K. His main areas of research include relational rituals, politeness and impoliteness, language games and performances, and intercultural communication (with special interest in Sino-Western communication). He has published 17 volumes; his recent monographs include Relational Rituals and Communication (Palgrave Macmillan, 2013) and Understanding Politeness (with Michael Haugh, Cambridge University Press, 2013). He is Editor (together with Michael Haugh and Jonathan Culpeper) of the Handbook of Linguistic Politeness (Palgrave Macmillan).

Sara Mills is a Research Professor in Linguistics at Sheffield Hallam University, U.K. She has published on feminist linguistics (Feminist Stylistics; Language and Sexism; with Mullany Language Gender and Feminism), politeness theory (Gender and Politeness; with Kadar ed. Politeness in East Asia), critical theory (Discourse; Michel Foucault), and feminist postcolonial theory (Discourses of Difference; with Lewis ed Feminist Postcolonial Theory). 


\section{Editor contact details}

Michael Haugh*

School of School of Languages and Linguistics, Griffith University, Brisbane, QLD 4111, Australia

Dániel Z. Kádár ${ }^{1}$

School of Music, Humanities and Media, University of Huddersfield, Queensgate, Huddersfield, HD13DH, United Kingdom

Sara Mills ${ }^{2}$

Humanities Research Centre, Sheffield Hallam University, Owen Building, Sheffield S1 1WB, United Kingdom

* Corresponding author: Tel.: +61 73735 5150; fax: +61 7 3735-6766

${ }^{1}$ Tel.: +44 1484472910

${ }^{2}$ Tel.: +44 1142253863

Email addresses: m.haugh@griffith.edu.au (M. Haugh).

d.z.kadar@hud.ac.uk (D. Kádár).

S.L.Mills@shu.ac.uk (S. Mills). 